\title{
Algunos enunciados sobre las obras de los artistas huilenses que participaron en 15 salón regional de artistas de la zona sur
}

\author{
Some statements about the works of huilenses artists who \\ participated in 15 Regional Salon of Artists of the South Zone
}

Jaime Ruiz Solórzano

Magister en Historia, Universidad Nacional de Colombia Doctorando en Estudios Sociales, Universidad Externado de Colombia Universidad Surcolombiana. Neiva, Colombia jairuso@usco.edu.co

\section{Resumen}

El texto que se presenta, constituye un referente para explicar la imagen de la carátula, la contra carátula y demás ilustraciones, contenidas en la edición número veinte de la Revista Paideia Surcolombiana. El artículo tiene el propósito de realizar una revisión interpretativa de las prácticas artísticas, proyectos y obras de los artistas huilenses que participaron durante el año 2015 en el "Salón Regional de Artistas de la Zona Sur". El artículo contiene la introducción; la caracterización de las prácticas creativas montadas en el 15 Salón Regional de Artistas; los aportes que efectúan los creadores al arte y la sociedad del Departamento del Huila; y las respectivas conclusiones.

Palabras clave: arte, sociedad, prácticas artísticas, Departamento del Huila, Arte político.

\section{Abstract}

The text presented, works as a reference to explain the cover's image, the back cover and other illustrations contained in this twentieth edition of the Paideia Surcolombiana Journal. The article is intended to make an interpretative review of artistic practices, projects and Huilenses artists' works that participated during 2015 in the "Regional Hall of Artists of the South Zone". The article contains the introduction; characterization of creative practices displayed in the 15th Regional Hall of Artists; the contributions made by creators to art and society from Huila department; and the respective conclusions.

Keywords: art, society, art practices, Huila Department, political art.

\section{Introducción}

Dentro de la selección de veintiséis artistas, incluidos en el pasado 15 "Salón Regional de Artistas de la Zona Sur" $(2015)^{1}$ se destaca la presencia de cinco artistas huilenses y dos creadores que han residido durante varios años en el Departamento del Huila. Estos artista son Jader Rivera (1964, Teruel), Magaly Cerquera Sáenz (1970, Neiva), Albeiro Naranjo Correa (1971, Pitalito), Yorleny Cardozo (1987, Pitalito), Paola Tafur (1982, Neiva), Gustavo Bermeo (1951, Bogotá) y Rafael Flórez (1973, Bogotá).
Se debe precisar que las obras registradas en el catálogo publicado en papel y de manera digital no dan cuenta de la totalidad de los proyectos, en la medida que incluyen solamente las particularidades más destacadas a nivel de las imágenes que ofrecen las obras, es como si primara un interés de espectacularidad publicitaria más que ofrecer una mayor información visual; tampoco permite percibir aspectos del montaje, tal y como se había realizado en los anteriores catálogos de los pasado Salones Regionales (2005, 2007, 2009); de igual forma los textos explicativos escasamente superan un ejercicio

1 - Según el Ministerio de Cultura la Zona Sur se encuentra se encuentra conformada por los departamentos de Tolima, Huila, Caquetá, Putumayo y Nariño 
básico de pregrado, siendo notable la ausencia de teóricos que respalden las afirmaciones planteadas y contribuyan a ampliar los márgenes de interpretación dentro de la cultura visual mundial.

Desafortunadamente no tuvimos la oportunidad de asistir a ninguno de los montajes de la exposición, especialmente la del Centro Cultural de Pitalito, donde se produjo la inauguración. Aún consideramos poco estratégico el hecho de haber abandonado las magníficas y bien cuidadas instalaciones que ofrece el Museo de Arte Contemporáneo del Huila - MACH y la gran capacidad de gestión de su directora; esto bajo el entendido que se quiera reconocer o no, el mayor polo de actividad cultural y localización de cantidad de públicos se encuentran en Neiva y su área de influencia.

En esencia percibimos una evidente deficiencia en la calidad de la impresión, como del contenido textual del catálogo. Probablemente, la crisis económica y las políticas de austeridad que afectan a las instituciones oficiales, se encuentran incidiendo negativamente en los anteriores aspectos. Respecto al montaje en Pitalito, pudo prevalecer un afán localista, encaminado a contribuir al exhibicionismo político de turno, cobijado con la necesidad de llevar a cabo "la descentralización cultural y la alternancia de espacios expositivos". Una eventual solución pudo haber sido, incluir un mayor número de artistas y haber empleado tanto el Centro Cultural de Pitalito como el recinto del MACH de Neiva.

No obstante, consideramos que lo más valioso y acertado fue el proceso curatorial implementado para la selección de los y las artista; caracterizado por el seguimiento personalizado de los proyectos y la acumulación del acervo documental. En la medida que las obras permiten leer las tendencias y particularidades del arte visual departamental actual.

A continuación aventuramos algunos enunciados interpretativos sobre las prácticas artísticas seleccionadas, atendiendo a las siguientes cuestiones: ¿Por qué se particularizan las prácticas creativas de los artistas huilenses y residentes, mostradas en el 15 Salón Regional de Artistas de la Zona Sur? ¿Cuáles son los aportes que hacen al arte y la sociedad del Departamento del Huila? ¿Qué podemos concluir de los dos cuestionamientos anteriores?

\section{Las prácticas creativas de los artistas huilenses, mostradas en el 15 Salón Regional de Artistas}

Reflexionando sobre los anteriores tópicos inicialmente podemos decir que los y las artistas trabajan sobre procesos de representación y de presentación, donde se particularizan tres grupos. En el primero son evidentes las prácticas artísticas que implican un nexo fuerte con el arte ancestral, tradicional y telúrico; un segundo trabaja con la valiosas lecciones inauguradas con la vanguardia, en el sentido que plantean interpretaciones de la subjetividad, para ello alternan las pulsiones personales y los conflictos sociales; el tercero próximo a las expresiones postminimalistas, evidencian propuesta feministas y contra el consumo masivo. Las prácticas artísticas abordan problemáticas derivadas de los fenómenos producidos por la mundialización.

Del primer grupo es notorio que la escultura titulada "N.N." de Albeiro Naranjo (ver pag. 13) constituya un indicio de la apropiación efectuada de los monumentos provenientes de San Agustín. Claro el tratamiento es otro, ya que la piedra fue sustituida por piezas y fragmentos de material metálico, que han sido soldados para articular la forma de la pieza; mientras la paleta emblemática de la cultura agustiniana: negro, rojo, amarillo y blanco originales, relacionados con los ciclos de vida-muerte-vida ${ }^{2}$, son sustituidos por colores y texturas metalizadas. El contenido puede relacionarse con el permanente ataque de la biopolítica que sufren las culturas sobrevivientes al genocidio producido desde la violenta conquista hispánica; los procesos de resistencia por conservar los valores de las culturas ancestrales; los movimientos de las comunidades para recuperar las tierras usurpadas durante las distintas colonizaciones; y lo más clara advertencia sobre la pretensión que tienen las transnacionales que proyectan hacer de la zona arqueológica una represa generadora de energía.

El ensamble titulado "Sueños desplazados" creado por Yorleny Cardozo (ver pág. 71) es una figuración antropo-zoomorfa que semeja un ave carroñera con cabeza de persona. No se trata solamente de una alusión surrealista semejante a las obras elaboradas por Marx Ernst cuando con sus fotomontajes y pinturas creo seres fantásticos de pesadilla, hibridando aves o peces y figuras humanas, ni de las piezas precolombinas que sincretizan imágenes de similar cualidad. La connotación de la obra alude a la ya denunciada depredación y dilapidación de los recursos naturales del Departamento del Huila, llevada a cabo con la construcción de la Represa del Quimbo. Se trata de testimoniar el alto volumen de árboles talados, la destrucción del hábitat de varias especies animales, la anegación de tierras cultivables y de componentes importantes del patrimonio material, en un área de 8.250 hectáreas. Sobre todo se refiere al desplazamiento pagado o forzado al que fueron sometidos los pobladores, violentando sus maneras de producción y de relación social, las memorias y los recuerdos, los imaginarios e ideales forjados en el territorio sumergido ${ }^{3}$.

2 - VELANDIA Jagua, César Augusto (1994). San Agustín. Arte, estructura y arqueología. Bogotá: Fondo de promoción de la cultura del Banco Popular-Universidad del Tolima, p. 85 .

3 - DIARIO DEL HUILA (2015). Las tristezas que deja el Ouimbo Neiva, abril 21, Disponible en http:/www diariodelhuila com/el-quimbo/lastristezas-que-deja-el-quimbo-cdgint20150421074952158 Consultada abril 2 de 2016 . Dice este periódico "Para generar apenas el 5 por ciento de la energía que requiere el país, fue necesario acabar con la tranquilidad de los habitantes de Gigante, El Agrado, Garzón, Tesalia, Altamira y Paicol, unas 300.000 personas, aproximadamente". 
Las seis estructuras piramidales que hacen parte de la instalación denominada "Cordillerano", (ver pág. 25) propuesta por Gustavo Bermeo, contienen en las paredes laterales elementos simbólicos referenciados en los pictogramas y petroglifos precolombinos, colores alusivos a los cuatro elementos de la naturaleza y los fenómenos atmosféricos; de hecho las formas de soporte son abstracciones de montañas. Probablemente el artista busca compartir una traducción visual del paisaje vivenciado cotidianamente, mientras motiva a tomar partido por la "madre tierra" y a experimentar los componentes estéticos del paisaje natural. Tanto los módulos piramidales y sus paramentos son componentes básicos para la construcción de las topografías interiores, que hacen parte de la rica tradición del arte telúrico latinoamericano ${ }^{4}$.

En el segundo grupo la serie fotografía llamada "Mundos paralelos", (ver pág. 33) captadas por Jader Rivera y montadas como un video, nos hablan de umbrales de existencias cotidianas y mundos alternos: visiones-pesadillas rurales y objetos ruinosos transmutados en fetiches; muebles y personas que parecen levitar; percepciones normales y cuasi místicas; animales congelados por la suerte de vivir; extensiones del placer y del dolor. En esencia son creaciones bastante entroncadas con las denominadas mitologías personales, cargadas de simbolismos subjetivos, crípticos; que tal vez obedezcan a los avatares de "las máquinas deseantes", como las denominan los filósofos Gilles Deleuze y Felix Guattari ${ }^{5}$.

Sobre esta pauta del neobarroco hecho imagen también versa la instalación titulada "Rudo despertar", creada por Magaly Cerquera Sáenz (ver portada y contraportada), se compone de dos pinturas e igual número de objetos escultóricos modelados con materiales endebles y prefabricados que son protegidos por urnas de acrílico. El mundo de esta artista incluye citas del arte universal, iconos mediáticos, símbolos de dominio e insinuaciones de su propia experiencias de vida. Las imágenes que representa son únicamente un pretexto para comentar de manera irónica la violenta realidad en la que convivimos, como un hecho complejo sin solución, al ser cruzado por el exterminio y la corrupción. En este sentido la instalación expresa las apreciaciones que posee la artista sobre algunos acontecimientos de la violencia política que ha vivido el país entre 1948 y 2014; al tiempo simboliza los 6 millones de víctimas, incluyendo 5 millones de desplazados, que ha produ-cido la guerra interna entre los años 1985 y $2012^{6}$. En sí, el conjunto de piezas se refiere a las familias colombianas que tienen de manera directa o indirecta un pariente, amigo o vecino, que han sido víctimas de la guerra interna. Paradójicamente, en el momento de creación de las obras, se reconocía a nuestra patria como uno de los países más felices del mundo ${ }^{7}$, aunque esta tendencia social ya no es tan cierta en la actualidad.

En el tercer grupo se encuentra el video-instalación producida como el registro de la acción corporal que tiene el nombre de "Hembra-Hambre" de Paola Tafur (ver pág. 45). En la acción la artista lleva a cabo una performance donde productos de cocina son tamizados sobre la palabra "Hambre", inscrita sobre el piso; es decir, dispone un material aromatizante y colorido asociado a las labores de cocina, sobre un concepto adherido a un material rígidamente sedimentado; al tiempo los movimientos del cuerpo denotan los roles tradicionales que ponen en común el sometido de la mujer. Tal ruptura con la asociación de los conceptos hembra-hambre, asumidos como mención de las necesidades insatisfechas, puede motivar la reflexión y la resignificación sobre la instrumentalización de los cuerpos que le importan al sistema; al tiempo que se vislumbran los cuerpos y los roles que habrán de emerger, como un efecto de la crítica social que se plantea. Según reflexiona Judith Butler $^{8}$, es posible que esta propuesta de arte feminista movilice a través de las prácticas de reiteración y alteración, la des-identificación inherente a aquellas normas reguladoras "mediante las cuales se materializa la diferencia sexual".

A este grupo también corresponde la instalación realizada con un seriado bajo el título de "Actos de liberación", de Rafael Flórez (ver pág. 53). Se trata de trescientas piezas modeladas en terracota que figuran liebres similares, con algunos cambios formales. En el montaje cada pieza se alza sobre las patas traseras, al tiempo que sus orejas levantadas expresan una actitud de interés y concentración. En conjunto las representaciones conforman una especie de círculo, concentrado bajo un foco de luz que pende de la parte superior. Tal vez, las liebres sean una metáfora de los seres humanos de la era hipermoderna, caracterizada por el predominio de las pantallas, la manipulación mediática, el consumo desaforado y la asunción de valores espurios, que subsumen al homo consumericus en la era del vacío y la decepción ${ }^{9}$.

4 - GUTIÉRREZ VIÑUALES, Rodrigo (director) (2005). Arte latinoamericano del siglo XX: otras historias de la Historia. Zaragoza: Prensas Universitarias de Zaragoza, p.167-189.

5 - DELEUZE, Guilles y GUATTARI, Feliz (2004). El Anit Edipo. Capitalismo y esquizofrenia. Barcelona: Paidós. P. 1 1-54.

6 - EL TIEMPO. Conflicto armado deja más de 6 millones de víctimas: Gobierno. Bogotá, 7 de febrero de 2014 . Disponible en

http://www.eltiempo.com/archivo/documento/CMS-13465935, Consultada, 25 de agosto de 2014.

7 - REVISTA SEMANA. Colombianos, los más felices otra vez. Bogotá, Enero 11 de 2014. Disponible en

http://www.semana.com/nacion/articulo/colombianos-los-mas-felices-otra-vez/370482-3 Consultada, 25 de agosto de 2014.

8 - BUTLER, Judith (2002). Cuerpos que importan. Sobre los límites materiales y discursivos del "sexo". Buenos Aires: Paidós, p. 21.

9 - LIPOVETSKY, Gilles (2000). La era del vacío. Ensayos sobre el individualismo contemporáneo. Madrid: Anagrama. 


\section{Los aportes realizados a la sociedad y los procesos artísticos del departamento del Huila}

En cuanto a los aportes que efectúan estas obras a la sociedad y los procesos artísticos y sensibles del Departamento del Huila, el primer grupo de prácticas artísticas contribuye a testimoniar de manera visual el saqueo de los recursos naturales, y los efectos sobre el medio ambiente y las poblaciones, realizados por las empresas nacionales y trasnacionales, como diría David Harvey, dentro de la lógica de la "acumulación por desposesión"10.

De otra parte, según Achille Mbembe, actualmente en varios países de Africa y del Tercer Mundo se ejercer la llamada "Necropolítica". Se trata de un poder paralelo al del Estado, basado en la "economía de la muerte", que se ejerce empleando mecanismos violentos, para someter o desplazar a los pobladores por medio del terror, y acumular grandes capitales recurriendo al despojo y la extorsión ${ }^{11}$. Como alternativa a la crisis ecológica-social y como una manera de tomar conciencia, los artistas también invitan a valorar, en los niveles patrimonial y estético, los paisajes del territorio propio.

El segundo grupo destaca la situación crítica del terror que ha producido durante 68 años la permanencia de la violencia política, causadas por los "dueños de la guerra" en la sociedad colombiana; explica Jean-Luc Nancy que "la guerra es necesariamente la guerra de los Soberanos, o más bien, no hay guerra sin Señores de la Guerra"12; reflexión que sirve para comprender el accionar del exterminio determinado por distintos actores, motivados por intereses económicos y de poder específicos.

En este sentido, los artistas a través de una serie de imágenes situadas en el neobarroco, "con un ojo en el pasado y otro en el presente ${ }^{113}$ traen los hechos acaecidos como un continuum del desastre y la miseria social al momento actual, conectando la "teatralización de los excesos"14 con los dramas familiares; percibidos y representados como experiencias de pesadillas y fugas de la realidad; recurren para ello al abigarramiento de las representaciones escultóricas, pictóricas y fotográficas.

El tercer grupo realiza aportes al arte feminista iniciado en los años 80 , como parte de las reivindicaciones exigidas por las minorías críticas de la cultura patriar- cal y falo-céntrica; que para el caso, ha determinado los roles de los géneros a través de las tejne de sujeción, implementas por nuestras culturas, desde el momento que fueron enraizadas en los valores la Iglesia Tradicional $^{15}$.

Así mismo, se establece de manera metafórica una denuncia de la introyección producida por el fenómeno del consumismo postindustrial, difundido a través de los medios de comunicación impresa, electrónica y digital; percibida como un "didáctica generadora de necesidades"; los cuales, según Foucault, son eficientemente diseñados y difundidos como parte de la "tecnología política del cuerpo".

El ambiente de aprendizaje de la mencionada didáctica se basa en la reiteración obsesiva de imágenes que ofrecen prestigio, lujo, calma y voluptuosidad; difundidas en los hogares, en los espacios de encuentro y de tránsito, con la intensión de ocasionar el "voraz apetito del consumo"; comprendiendo que esta tecnología visual y narrativa pretende orientar de manera permanente la repartición de alineaciones ideológicas, el control social masivo, y el hiperconsumo, analizado por Guilles Lipovestky en varios de sus trabajos ${ }^{16}$.

Según Foucault la sujeción y manipulación de los cuerpos se puede efectuar recurriendo a medios directos como el uso de la violencia, las armas, el terror; o a través de medios indirectos que son diseñados, organizados, y aplicados de manera técnica e imperceptible, como puede ser los supuestos religiosos y culturales, el adoctrinamiento ideológicos, la manipulación con imágenes y consignas, los salarios inequitativos, las necesidades básicas insatisfechas, la carencia de educación, la construcción mediática de imaginarios falaces $^{17}$.

\section{Conclusiones}

Si bien es cierto que el mundo del arte actual ha descalificado la sensibilidad social y las prácticas artísticas referenciadas en problemáticas sentidas, debido a que las practicas de acumulación promueven el sentir "apolítico" de los creadores; generalmente cooptados por la publicidad, el mercado y la política institucionalizada para promocionar deseos y valores ideológicos, inquirimos ¿Quienes más que los mismos artistas conscientes, como parte del sensorium de la sociedad, pueden encarnar el sentir de los fenómenos y las contradicciones sociales? Según Suzanne Lacy el "Hacer de "sí-mismo" es un conducto para la expresión de un grupo social entero puede ser un acto de profunda empatía. La empatía de la experiencia subjetiva

10 - HARVEY, David. El "nuevo" imperialismo: acumulación por desposesión. Disponible en

http://www. cronicon.net/paginas/Documentos/No.22.pdf Consultada abril 2 de 2016.

11 - MBEMBE, Achille (2011). Necropolítica. Barcelona: Melusina, p. 89-95.

12 - NANCY, Jean-Luc (2006). Ser singular plural. Madrid: Arena, p. 118. Para Nancy los Soberanos son también los jefes o comandantes. Mientras

la guerra es una "tejne (técnica), arte, operación o ejecución de la Soberanía misma".

13 - GUASCH, Anna María (2007). El arte último del siglo XX. Del posminimalismo a lo multicultural Madrid: Alianza, p. 429.

14 - BLAIR TRUJILLO, Elsa (2004). Muertes Violentas: La teatralización del exceso. Medellín: Universidad de Antioquia.

15 - NANCY, Jean-Luc (2006). Ser singular plural. Op. Cit., p. 133-134.

16 - LIPOVETSKY, Gilles (2007). La felicidad paradójica. Ensayo sobre la sociedad de hiperconsumo. Barcelona: Anagrama.

17 - FOUCAULT. Michel (2002). Vigilary castigar. Nacimiento de la prisión. Buenos aires: Siglo XXI, p. 32-33. 
vista en una obra de arte es un servicio que los artistas ofrecen al mundo"1s.

Desde esta perspectiva, la revisión de las obras producidas por los artistas huilenses y residentes, participantes en el 15 Salón Regional de Artistas de la Zona Sur, indica que las prácticas, los proyectos y las obras correspondientes al año 2015 se encuentran directamente relacionados con la definición del Arte Político establecido por mainstream artístico.

Lo anterior cobra plena validez si consideramos, junto con Peter Sloterdijk, que asistimos actualmente a una revolución en el campo del arte como herencia cultural del siglo XX; ella es articulada en dos dinámicas. De una parte, la liberación de las normas de creación y la expansión de todas los posibilidades de "expresión y de construcción"; de otro lado, la permanente "ampliación del concepto de arte", abarcando prácticas o poéticas visuales anteriormente descalificadas. Ambas con todas sus particiones estéticas y sus propagaciones político-culturales; por lo cual, "Cada vez mayores fragmentos de la realidad se convierten en materia prima para la producción en material de partida para imágenes, relaciones, transformaciones" ${ }^{19}$.

Razones por las cuales, el arte político actual representa y presenta tales dimensiones por medio de diversos medios y objetos artísticos, además de difundir las reflexiones y los argumentos críticos que surgen de los eventos históricos y culturales, las problemáticas y los acontecimientos actuales, los ideales y las aspiraciones de las comunidades o de los creadores.

Así mismo, podemos decir que existe una trayectoria consolidada del arte político nacional y que se asiste a su consolidación, a nivel regional; acumulado que se pueden rastrear en las expresiones artísticas que aluden a este tópico de creación a través del tiempo, en nuestros contextos socio-culturales y departamen- tales. Sin embargo, al considerar que el arte, como práctica teórica-creativa, crítica y testimonial, no tiene el poder de incidir de manera definitiva en la transformación de las llamadas contradicciones sociales, los artistas se comprometen con roles de participación personal, frente a los fenómenos de la realidad.

Razón por la cual podemos considerar que los artistas del Departamento del Huila pueden estar tomando posiciones, sin tener en cuenta las exigencias de cualquier ideología, principios políticos establecidos o afiliaciones partidistas; sus creaciones son prácticas artísticas que plantean preguntas a los públicos ante la identificación de circunstancias que afectan los territorios, rompen con el consenso, dinamizan la violencia, o afectan a la mayoría de ciudadanos

Prácticas artísticas, proyectos y obras que son socializadas ante distintos públicos, probablemente, con el fin de develar las paradojas del sistema económicopolítico y los mecanismos subyacentes en el ordenamiento social; cuestionar y efectuar aportes a la reflexión o a la movilización; contribuir a la reconstrucción social, aportar referentes de testimonio o memoria; o incentivar la organización y la participación de comunidades municipales en experiencias reales.

Con lo anterior queda demostrado que los artistas del Departamento no han desistido, como afirma Marc Jiménez, ni se han "replegado sobre sí mismos, renunciando a involucrarse en el campo social y político, sólo obsesionados por las fluctuaciones del mercado... Una simple ojeada a las obras recientes revelan la sorprendente diversidad de preocupaciones vinculadas a la realidad más tangible, ya sea social, política, religiosa o ideológica" ${ }^{120}$. También es nuestro ideal.

18 - LACY, Suzanne (2003). Hacer arte público como memoria colectiva, como metáfora, y como acción. En RIAÑO ALCALÁ, Pilar, LACY, Suzanne y AGUDELO HERNÁNDEZ, Olga Cristina. Arte, memoria y violencia. Reflexiones sobre la ciudad. Medellín. Corporación Región, pág. 36.

19 -SLOTERDIJK, Peter. El arte se repliega en símismo. En Revista Observaciones Filosóficas. Disponible en:

http://www.observacionesfilosoficas.net/elarteserepliega.html Consultada enero 9 de 2016.

20 - JIMÉNEZ, Marc (2010). La querella del arte contemporáneo. Buenos Aires: Amorrortu, p. 267. 